\title{
Ischaemic and bleeding outcomes in elderly patients undergoing a prolonged versus shortened duration of dual antiplatelet therapy after percutaneous coronary intervention: insights from the PRODIGY randomised trial
}

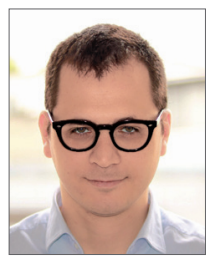

Raffaele Piccolo $^{1}$, MD; Giulia Magnani ${ }^{1}$, MD, PhD; Sara Ariotti ${ }^{1,2}, \mathrm{MD}$; Giuseppe Gargiulo $^{1,3}$, MD; Marcello Marino ${ }^{1}$, MD; Andrea Santucci ${ }^{1,4}$, MD; Anna Franzone ${ }^{1}$, MD; Matteo Tebaldi ${ }^{5}$, MD; Dik Heg ${ }^{6}$, PhD; Stephan Windecker ${ }^{1}$, MD; Marco Valgimigli ${ }^{1,2 *}, \mathrm{MD}, \mathrm{PhD}$

1. Bern University Hospital, University of Bern, Bern, Switzerland; 2. Thoraxcenter, Erasmus Medical Center, Rotterdam, the Netherlands; 3. Federico II University, Naples, Italy; 4. Division of Cardiology and Cardiovascular Pathophysiology, University of Perugia, Perugia, Italy; 5. Cardiovascular Institute, Azienda Ospedaliero-Universitaria di Ferrara, Ferrara, Italy; 6. Institute of Social and Preventive Medicine and Clinical Trials Unit, University of Bern, Bern, Switzerland

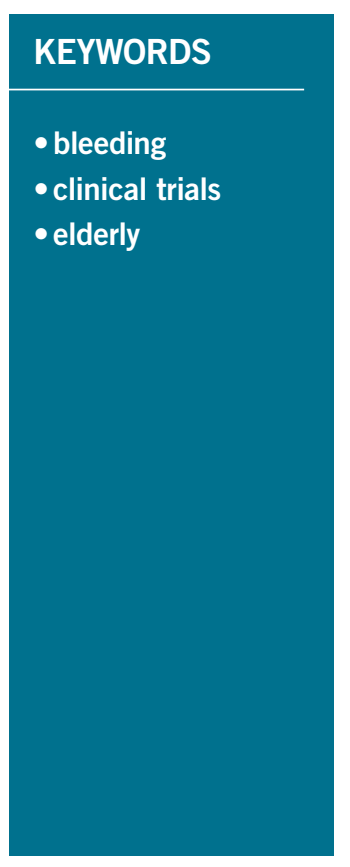

\begin{abstract}
Aims: The aim of this study was to evaluate the efficacy and safety of 24-month vs. six-month dual antiplatelet therapy (DAPT) among elderly ( $\geq 75$ years) and non-elderly patients ( $<75$ years) undergoing percutaneous coronary intervention.

Methods and results: The primary efficacy endpoint of the PRODIGY trial was the composite of death, myocardial infarction, or cerebrovascular accident at 24-month follow-up. The key safety endpoint was type 2, 3 or 5 bleeding according to the BARC criteria. Of 1,970 participants, 587 (29.8\%) were elderly and had a higher risk of adverse events compared with younger patients. The risk of the primary endpoint was not significantly reduced with 24-month compared to six-month DAPT among both elderly (HR 0.80, 95\% CI: $0.55-1.16, p=0.24$ ) and non-elderly patients (HR 1.48, 95\% CI: $0.95-2.30, p=0.08$ ), although interaction testing was significant $(\mathrm{p}=0.036)$. A 24-month versus six-month DAPT significantly increased the risk of BARC type 2, 3 or 5 bleeding in both older (HR 1.90, 95\% CI: 1.06-3.38, p=0.03) and younger patients (HR 2.54, 95\% CI: 1.43-4.53, p=0.002, p-interaction=0.48). However, measures of absolute risk difference indicated a less favourable safety profile of prolonged DAPT for older rather than younger patients.
\end{abstract}

Conclusions: In the PRODIGY trial, prolonging clopidogrel-based DAPT beyond six months in elderly patients increased the risk of bleeding, without affording a significant prevention of ischaemic events.

\footnotetext{
*Corresponding author: Department of Cardiology, Bern University Hospital, University of Bern, 3010 Bern, Switzerland. E-mail: marco.valgimigli@insel.ch
} 


\section{Abbreviations}

$\begin{array}{ll}\text { BARC } & \text { Bleeding Academic Research Consortium } \\ \text { CVA } & \text { cerebrovascular accident } \\ \text { DAPT } & \text { dual antiplatelet therapy } \\ \text { GUSTO } & \text { Global Utilization of Streptokinase and Tissue } \\ & \text { Plasminogen Activator for Occluded Arteries } \\ \text { MI } & \text { myocardial infarction } \\ \text { PCI } & \text { percutaneous coronary intervention } \\ \text { TIMI } & \text { Thrombolysis In Myocardial Infarction }\end{array}$

\section{Introduction}

Elderly individuals account for an increasing proportion of patients with coronary artery disease undergoing percutaneous coronary intervention (PCI), due to the ageing of the population with increased life expectancy ${ }^{1-3}$. Dual antiplatelet therapy (DAPT) with aspirin and oral $\mathrm{P} 2 \mathrm{Y}_{12}$ adenosine diphosphate receptor inhibitors represents the standard of treatment to prevent new atherothrombotic events after PCI, yet its optimal duration remains controversial ${ }^{4-6}$. Results from randomised trials and meta-analyses indicate that extended (i.e., $>12$ months) duration of DAPT is associated with a lower risk of ischaemic events, even though this benefit is partly offset by a higher risk of clinically relevant bleeding ${ }^{7-9}$. However, extrapolating such findings to elderly patients is challenging in view of the increased risk of bleeding and ischaemic events occurring in this subgroup. In addition, elderly individuals have been underrepresented among randomised trials that evaluated different durations of DAPT following PCI. The Prolonging Dual Antiplatelet Treatment After Grading Stent-Induced Intimal Hyperplasia Study (PRODIGY) compared a strategy of DAPT extended to 24 months with a shorter course of DAPT up to six months in a broadly inclusive population of PCI patients, with the inclusion of a relatively high proportion of elderly participants ${ }^{10}$.

Therefore, we sought to evaluate the impact of age in modulating the hazard of ischaemic and bleeding events and to investigate the outcomes of 24-month vs. six-month DAPT in elderly ( $\geq 75$ years) vs. younger patients $(<75$ years) enrolled in the PRODIGY trial.

\section{Methods}

Details on study design and primary results of the PRODIGY trial have been reported elsewhere ${ }^{10}$. Briefly, all-comer patients undergoing treatment with a balanced mixture of stents were randomly allocated at 30 days to either up to six months or to 24 months of DAPT. The ethics committees of the participating centres independently approved the protocol and all participants gave written informed consent.

\section{TREATMENT PROTOCOL}

All patients received aspirin (80-160 mg orally indefinitely) and clopidogrel ( $75 \mathrm{mg} /$ day) according to the randomisation scheme as follows: for either up to six months in the short DAPT group or to 24 months in the prolonged DAPT arm, irrespective of the previously implanted stent type or indication for PCI.

\section{STUDY ENDPOINTS}

The primary efficacy endpoint of the PRODIGY trial was the composite of death, myocardial infarction (MI), or cerebrovascular accident (CVA), whereas the key safety endpoint included Bleeding Academic Research Consortium (BARC) type 2, 3, or 5 bleeding. Other endpoints included each component of the primary efficacy endpoint, cardiovascular death, stent thrombosis defined on the basis of the Academic Research Consortium criteria, and BARC type 3 or 5 bleeding. Additional safety endpoints were bleeding events adjudicated according to the Thrombolysis In Myocardial Infarction (TIMI) and the Global Utilization of Streptokinase and Tissue Plasminogen Activator for Occluded Arteries (GUSTO) criteria. More detailed definitions of the endpoints have been provided previously ${ }^{11}$. A clinical events committee blinded to treatment allocation adjudicated all efficacy and bleeding events.

\section{STATISTICAL ANALYSIS}

Continuous variables are presented as mean \pm standard deviation and were compared with the Wilcoxon rank-sum test. Categorical variables are expressed as counts and percentages and were compared with chi-square or Fisher's exact tests as appropriate. We evaluated the effect of age, modulated as a continuous variable, on the risk of ischaemic and bleeding events in the overall population by means of multivariable-adjusted, restricted cubic splines with three knots of the distribution $\left(10^{\text {th }}, 50^{\text {th }}\right.$, and $90^{\text {th }}$ percentiles $)^{12}$. The effect of age on clinical events was analysed in the categories of patients $<75$ vs. $\geq 75$ years by using Cox regression analyses. Both analyses were adjusted for baseline clinical variables associated with the primary efficacy and key safety endpoints at the univariate analysis with a significance level of $p<0.20$. The efficacy and safety of 24-month DAPT vs. six-month DAPT for elderly ( $\geq 75$ years) vs. non-elderly ( $<75$ years) patients was evaluated at 24 months. Clinical events were expressed as counts with rates computed according to the Kaplan-Meier method. Cox regression analysis was used to calculate hazard ratios (HRs) with $95 \%$ confidence intervals (CIs) and an interaction test was provided to evaluate the effect of treatment in the elderly vs. non-elderly. Sensitivity analyses were conducted to evaluate the efficacy and safety of DAPT from six to 24 months by using a landmark analysis and to assess whether results were consistent by applying the cut-off of 65 years to define the elderly status. In addition, we evaluated the risk of deaths associated or not with MI if they occurred within a sevenday window from MI onset. Risk difference and the number needed to treat for benefit or harm (NNTB or NNTH) with relative $95 \%$ CI were also provided in order to account for absolute risk estimates. Finally, the interaction between treatment effect and ageing, modelled as a continuous variable, was analysed with a fractional polynomial interaction ${ }^{13}$. All p-values are two-sided and statistical significance was assumed for $\mathrm{p}<0.05$. All analyses were carried out with Stata Statistical Software, Release 13 (StataCorp LP, College Station, TX, USA). 


\section{Results}

Of 1,970 participants enrolled in the PRODIGY trial, 587 (29.8\%) patients were $\geq 75$ years of age and 1,383 (70.2\%) patients were $<75$ years of age. As shown in Table 1 and Table 2, baseline and periprocedural features were largely comparable within the elderly vs. non-elderly groups between patients assigned to 24-month or six-month DAPT.

\section{EFFECT OF AGEING ON CLINICAL OUTCOMES}

There was a direct graded relationship between age and the risks of the primary efficacy or the key safety endpoint, with a steeper increase in the hazard trajectories beyond 70 years of age (Figure 1). A similar direct association between age and bleeding events was observed for BARC type 3 or 5, TIMI minor or major, or GUSTO moderate or severe bleeding (data not shown). When dichotomised, patients with age $\geq 75$ years compared with younger participants had a higher risk of death, MI or CVA and BARC type 2, 3 or 5 bleeding.

\section{EFFICACY OF PROLONGED DAPT AMONG ELDERLY VS. NON-ELDERLY PATIENTS}

Figure 2A shows the analysis of efficacy endpoints at two-year follow-up. There was a significant interaction $(p=0.036)$ between

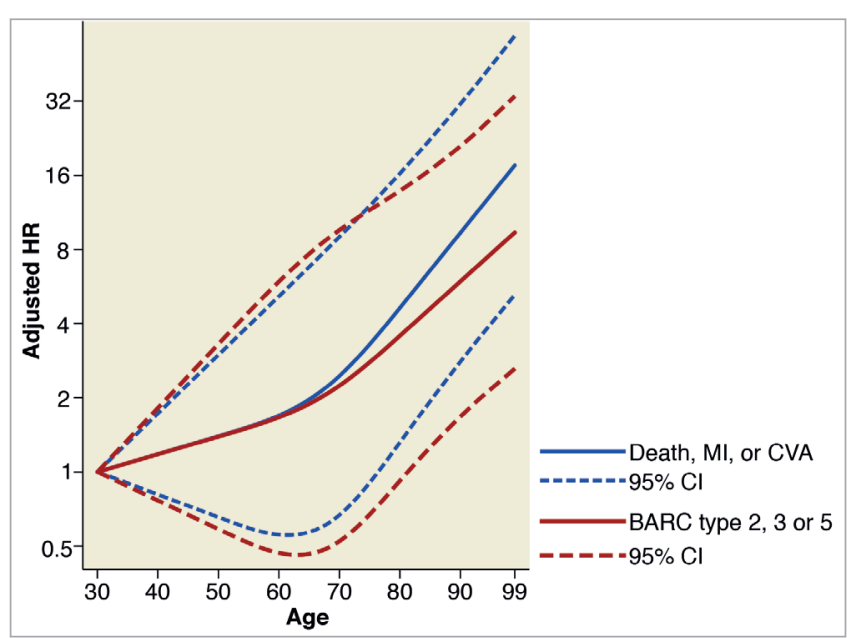

Figure 1. Multivariable-adjusted spline curves for the HR of the primary ischaemic and bleeding endpoint vs. age modelled as a continuous variable. Patients with age $\leq 30$ years represent the referent group with the HR set to 1 . The dotted lines represent the $95 \%$ $C I$ of the hazard function. The variables used for the adjustments are listed in the Methods section. BARC: Bleeding Academic Research Consortium; CI: confidence intervals; CVA: cerebrovascular accident; HR: hazard ratio; MI: myocardial infarction

Table 1. Baseline characteristics.

\begin{tabular}{|c|c|c|c|c|c|c|c|}
\hline & \multicolumn{3}{|c|}{ Age $\geq 75$ years } & \multicolumn{3}{|c|}{ Age $<75$ years } & \multirow[b]{2}{*}{$\boldsymbol{p}$-interaction } \\
\hline & $\begin{array}{c}\text { 24-month } \\
\text { DAPT } \\
\mathrm{N}=283\end{array}$ & $\begin{array}{c}\leq 6 \text {-month } \\
\text { DAPT } \\
N=304\end{array}$ & p-value & $\begin{array}{c}\text { 24-month } \\
\text { DAPT } \\
\text { N=704 }\end{array}$ & $\begin{array}{c}\leq 6-\text { month } \\
\text { DAPT } \\
N=679\end{array}$ & $p$-value & \\
\hline Age, years & $80.2 \pm 3.7$ & $80.6 \pm 4.3$ & 0.47 & $62.9 \pm 9.1$ & $62.3 \pm 8.7$ & 0.07 & 0.19 \\
\hline Male & $186(65.7)$ & $200(65.8)$ & 1.00 & $578(82.1)$ & $547(80.6)$ & 0.49 & 0.64 \\
\hline $\mathrm{BMI}, \mathrm{kg} / \mathrm{m}^{2}$ & $26.8 \pm 9.5$ & $26.4 \pm 3.6$ & 0.58 & $28.1 \pm 13.3$ & $28.1 \pm 11.4$ & 0.22 & 0.78 \\
\hline Hypertension & $232(82.0)$ & $237(78.0)$ & 0.26 & $489(69.5)$ & $456(67.2)$ & 0.39 & 0.54 \\
\hline Dyslipidaemia & $142(50.2)$ & $149(49.0)$ & 0.81 & $411(58.4)$ & $376(55.4)$ & 0.28 & 0.70 \\
\hline Smoking & $18(6.4)$ & $29(9.5)$ & 0.17 & $204(29.0)$ & $218(32.1)$ & 0.22 & 0.38 \\
\hline Diabetes & $83(29.3)$ & $82(27.0)$ & 0.58 & $161(22.9)$ & $151(22.2)$ & 0.80 & 0.72 \\
\hline Insulin-treated diabetes & $17(6.0)$ & $22(7.2)$ & 0.62 & $42(6.0)$ & $33(4.9)$ & 0.41 & 0.31 \\
\hline Family history of CAD & $70(24.7)$ & $39(12.8)$ & $<0.001$ & $219(31.1)$ & $225(33.1)$ & 0.42 & $<0.001$ \\
\hline Previous MI & $93(32.9)$ & $93(30.6)$ & 0.60 & $177(25.1)$ & $163(24.0)$ & 0.66 & 0.84 \\
\hline Previous $\mathrm{PCl}$ & $47(16.6)$ & $64(21.1)$ & 0.17 & $142(20.2)$ & $106(15.6)$ & 0.03 & 0.018 \\
\hline Previous CABG & $44(15.5)$ & $40(13.2)$ & 0.41 & $66(9.4)$ & $63(9.3)$ & 1.00 & 0.54 \\
\hline Creatinine clearance, $\mathrm{mL} / \mathrm{min}$ & $53.6 \pm 19.7$ & $54.9 \pm 18.7$ & 0.28 & $89.7 \pm 44.8$ & $87.8 \pm 27.5$ & 0.82 & 0.32 \\
\hline Peripheral artery disease & $55(19.4)$ & $74(24.3)$ & 0.16 & $63(8.9)$ & $54(8.0)$ & 0.56 & 0.14 \\
\hline LVEF, \% & $49.8 \pm 10.6$ & $48.5 \pm 11.0$ & 0.12 & $51.5 \pm 10.0$ & $51.4 \pm 10.1$ & 0.92 & 0.20 \\
\hline Congestive HF or LV dysfunction & $24(8.5)$ & $21(6.9)$ & 0.54 & $16(2.3)$ & $19(2.8)$ & 0.61 & 0.35 \\
\hline Indication to $\mathrm{PCl}$ & & & 0.62 & & & 0.99 & 0.66 \\
\hline Stable CAD & $56(19.8)$ & $58(19.1)$ & 0.84 & $199(28.3)$ & $192(28.3)$ & 1.00 & \\
\hline NSTE-ACS & $149(52.7)$ & $151(49.7)$ & 0.51 & $262(37.2)$ & $255(37.6)$ & 0.91 & \\
\hline STEMI & $78(27.6)$ & $95(31.2)$ & 0.37 & $243(34.5)$ & $232(34.2)$ & 0.91 & \\
\hline Acute $\mathrm{MI}$ at presentation & $162(57.2)$ & $188(61.8)$ & 0.27 & $385(54.7)$ & $363(53.5)$ & 0.67 & 0.23 \\
\hline
\end{tabular}


Table 2. Angiographic and procedural characteristics.

\begin{tabular}{|c|c|c|c|c|c|c|c|}
\hline & \multicolumn{3}{|c|}{ Age $\geq 75$ years } & \multicolumn{3}{|c|}{ Age $<75$ years } & \multirow[b]{2}{*}{$\boldsymbol{p}$-interaction } \\
\hline & $\begin{array}{c}\text { 24-month } \\
\text { DAPT } \\
N=283\end{array}$ & $\begin{array}{c}\leq 6 \text {-month } \\
\text { DAPT } \\
N=304\end{array}$ & $p$-value & $\begin{array}{c}\text { 24-month } \\
\text { DAPT } \\
\text { N=704 }\end{array}$ & $\begin{array}{c}\leq 6-\text { month } \\
\text { DAPT } \\
N=679\end{array}$ & $p$-value & \\
\hline Angiographic features & & & 0.09 & & & 0.73 & 0.08 \\
\hline Single-vessel disease & $58(20.5)$ & $79(26.0)$ & & $234(33.2)$ & $220(32.4)$ & & \\
\hline Two-vessel disease & $84(29.7)$ & $100(32.9)$ & & 267 (37.9) & $250(36.8)$ & & \\
\hline Three-vessel disease & $141(49.8)$ & $125(41.1)$ & & $203(28.8)$ & 209 (30.8) & & \\
\hline Multivessel disease & $225(79.5)$ & $225(74.0)$ & 0.12 & $470(66.8)$ & 459 (67.6) & 0.78 & 0.13 \\
\hline Multivessel PCl & $88(31.1)$ & $98(32.2)$ & 0.79 & $165(23.4)$ & $175(25.8)$ & 0.32 & 0.74 \\
\hline$\geq 2$ treated lesions & $116(41.0)$ & $127(41.8)$ & 0.87 & $249(35.4)$ & 244 (35.9) & 0.87 & 0.97 \\
\hline$\geq 3$ treated lesions & $33(11.7)$ & $32(10.5)$ & 0.69 & $75(10.7)$ & $83(12.2)$ & 0.40 & 0.39 \\
\hline$\geq 4$ treated lesions & $10(3.5)$ & $14(4.6)$ & 0.54 & $28(4.0)$ & $30(4.4)$ & 0.69 & 0.74 \\
\hline \multicolumn{8}{|l|}{ Treated vessel } \\
\hline Left anterior descending artery & $151(53.4)$ & $161(53.0)$ & 0.93 & $367(52.1)$ & $357(52.6)$ & 0.87 & 0.86 \\
\hline Left circumflex artery & $113(39.9)$ & $93(30.6)$ & 0.02 & $208(29.5)$ & $225(33.1)$ & 0.16 & 0.006 \\
\hline Right coronary artery & $86(30.4)$ & $113(37.2)$ & 0.10 & 260 (36.9) & $250(36.8)$ & 1.00 & 0.14 \\
\hline Left main artery & $24(8.5)$ & $24(7.9)$ & 0.88 & $31(4.4)$ & $32(4.7)$ & 0.80 & 0.71 \\
\hline Saphenous vein graft & $7(2.5)$ & $7(2.3)$ & 1.00 & $16(2.3)$ & $10(1.5)$ & 0.32 & 0.59 \\
\hline At least one type B2/C lesion & $185(65.4)$ & $221(72.7)$ & 0.06 & 457 (64.9) & $443(65.2)$ & 0.91 & 0.12 \\
\hline At least one restenotic lesion & $7(2.5)$ & $15(4.9)$ & 0.13 & $38(5.4)$ & $33(4.9)$ & 0.72 & 0.12 \\
\hline Randomised stent & & & 0.58 & & & 0.88 & 0.45 \\
\hline Bare metal stent & $82(29.0)$ & $80(26.3)$ & & $164(23.3)$ & $166(24.4)$ & & \\
\hline Paclitaxel-eluting stent & $66(23.3)$ & $68(22.4)$ & & $182(25.9)$ & $177(26.1)$ & & \\
\hline Zotarolimus-eluting stent & $59(20.8)$ & $78(25.7)$ & & $186(26.4)$ & $167(24.6)$ & & \\
\hline Everolimus-eluting stent & 76 (26.9) & $78(25.7)$ & & $172(24.4)$ & 169 (24.9) & & \\
\hline Number of implanted stents & $1.9 \pm 1.3$ & $1.9 \pm 1.0$ & 0.22 & $1.8 \pm 1.2$ & $1.9 \pm 1.3$ & 0.52 & 0.59 \\
\hline Overall stent length, mm* & $38.6 \pm 28.8$ & $39.3 \pm 24.3$ & 0.26 & $39.3 \pm 30.8$ & $40.5 \pm 30.5$ & 0.53 & 0.87 \\
\hline Mean stent diameter, $\mathrm{mm}^{*}$ & $2.9 \pm 0.4$ & $3.0 \pm 0.4$ & 0.04 & $3.0 \pm 0.5$ & $3.0 \pm 0.5$ & 0.008 & 0.004 \\
\hline
\end{tabular}

age, dichotomised at age 75 years cut-off point, and the primary efficacy endpoint. Although the primary efficacy endpoint did not differ based on the randomly allocated DAPT duration among elderly patients, event rates were numerically lower for prolonged DAPT (HR 0.80, 95\% CI: 0.55-1.16, p=0.24). Conversely, a trend towards an increased risk of the primary endpoint was observed among younger patients randomised to 24-month vs. six-month DAPT (HR 1.48, 95\% CI: 0.95-2.30, p=0.08). This difference was mainly driven by cardiac mortality, which occurred more frequently among younger patients randomised to 24-month DAPT (HR 2.92, 95\% CI: 0.94-9.05, p=0.06). However, the age-bytreatment interaction was significant for deaths not related to MI $(p=0.043)$, but not for those related to MI $(p=0.81)$. The test for interaction for the primary endpoint was not significant $(p=0.10)$ from six to 24 months (Figure 2B). By using a cut-off of 65 years, there was no significant interaction $(\mathrm{p}=0.09)$ with 24 -month vs. six-month DAPT with respect to the primary ischaemic endpoint among patients $\geq 65$ years (HR 0.89, 95\% CI: 0.66-1.21, $\mathrm{p}=0.48$ ) vs. those $<65$ years (HR 1.75, 95\% CI: 0.86-3.58, $\mathrm{p}=0.13$ ).

\section{SAFETY OF PROLONGED DAPT AMONG ELDERLY VS. NON-ELDERLY PATIENTS}

Figure 3A shows the analysis of safety endpoints at two-year followup. BARC type 2, 3 or 5 bleeding was significantly increased in both elderly (HR 1.90, 95\% CI: 1.06-3.38, p=0.03) and non-elderly patients (HR 2.54, 95\% CI: 1.43-4.53, $\mathrm{p}=0.002$; $\mathrm{p}$ for interaction=0.48) randomised to 24-month versus six-month DAPT. The NNTH was lower for elderly (NNTH 18; 95\%CI: NNTH 119 to NNTH 10) than for non-elderly patients (NNTH 29; 95\%CI: NNTH 72 to NNTH 18). Although not significantly increased, bleeding events according to TIMI and GUSTO definitions were numerically higher in patients randomised to 24-month DAPT vs. six-month DAPT. In the analysis between six and 24 months (Figure 3B), the relative risks of BARC type 2, 3 or 5 bleeding were consistently higher in both patients aged $\geq 75$ years (HR 2.73,95\% CI: 1.26-5.89, $\mathrm{p}=0.01$ ) and patients $<75$ years (HR 2.73, 95\% CI: 1.37-5.44, $\mathrm{p}=0.004$, p for interaction=0.99). The corresponding NNTH for the two groups was 18 (95\%CI: NNTH 89 to NNTH 11) and 36 (95\%CI: NNTH 107 to NNTH 21), respectively. After six months, moderate or severe 


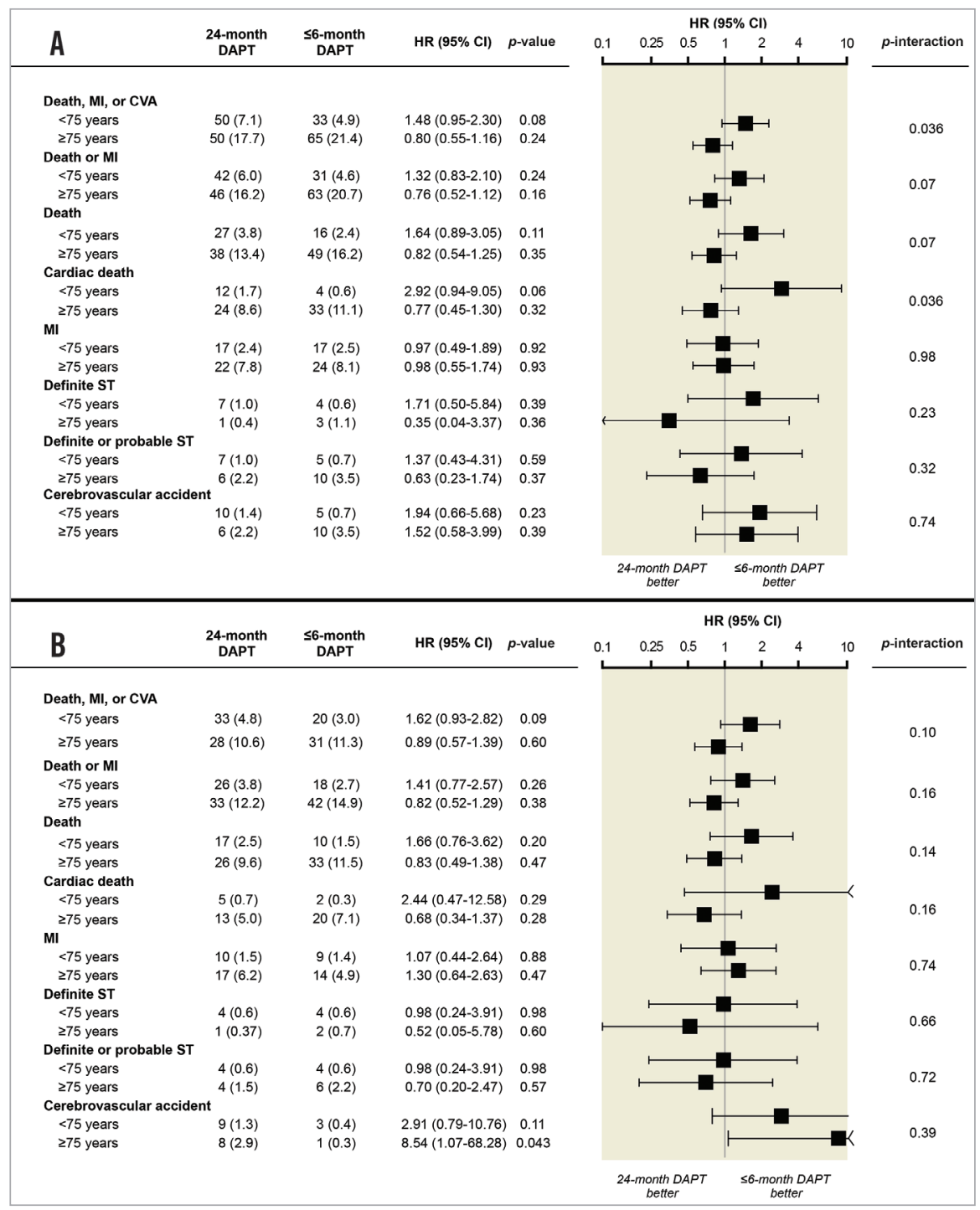

Figure 2. Analysis of efficacy outcomes stratified by age. A) Ischaemic events at 24 months. B) Ischaemic events from six to 24 months. CI: confidence intervals; CVA: cerebrovascular accident; DAPT: dual antiplatelet therapy; HR: hazard ratio; MI: myocardial infarction; ST: stent thrombosis

bleeding according to GUSTO criteria was significantly increased in elderly but not in younger patients treated with 24-month DAPT. The corresponding NNTH was NNTH $24(95 \% \mathrm{CI}$ : NNTH 78 to NNTH 13) for older vs. NNTH 194 (95\%CI: NNTB 198 to NNTH 58) for younger patients. A significant interaction $(p=0.007)$ for the absolute risk difference of moderate or severe GUSTO bleeding was present between older $(3.9 \%, 95 \% \mathrm{CI}: 1.1-6.8 \%)$ and younger groups $(0.04 \%$, 95\% CI: $-0.06 \%-1.5 \%$ ) after six-month follow-up. By using a cutoff of 65 years, there was no significant interaction $(p=0.49)$ with 24-month vs. six-month DAPT with respect to the primary bleeding endpoint among patients $\geq 65$ years (HR 1.96, 95\% CI: 1.23-3.31, $\mathrm{p}=0.004$ ) vs. those $<65$ years (HR 2.92, 95\% CI: $1.23-6.96, \mathrm{p}=0.02$ ).

\section{INTERACTION BETWEEN AGEING AND TREATMENT EFFECT OF DAPT}

The age-by-treatment interaction evaluated by fractional polynomial analyses was not significant for the primary efficacy $(p=0.35)$ and key safety endpoints $(\mathrm{p}=0.73$ ). For the composite of death, MI or CVA, the area representing the $95 \%$ CI treatment effect crossed the no effect line throughout all ages (Figure 4A). In contrast, the area of treatment effect for the key safety endpoint was above the line of no effect for a wide range of ages, indicating a harmful effect of 24-month over six-month DAPT in terms of bleeding complications for most age values (Figure 4B).

\section{Discussion}

The main findings of the present analysis of the PRODIGY trial can be summarised as follows.

1) Elderly patients undergoing PCI have a higher risk of ischaemic and bleeding events compared with younger patients, with a similar effect of ageing on the hazards of such events.

2) In both elderly and non-elderly patients, prolonging DAPT for 24 months did not reduce the risk of the primary efficacy endpoint of death, MI or CVA compared with a six-month DAPT. 


\begin{tabular}{|c|c|c|c|c|c|c|c|}
\hline \multirow{2}{*}{ A } & \multirow{2}{*}{$\begin{array}{c}\text { 24-month } \\
\text { DAPT }\end{array}$} & \multirow{2}{*}{$\begin{array}{c}\text { s6-month } \\
\text { DAPT }\end{array}$} & \multirow[b]{2}{*}{$\mathrm{HR}(95 \% \mathrm{Cl})$} & \multirow[b]{2}{*}{$p$-value } & \multicolumn{2}{|c|}{ HR $(95 \% \mathrm{Cl})$} & \multirow[b]{2}{*}{$p$-interaction } \\
\hline & & & & & $\begin{array}{llll}0.1 & 0.25 & 0.5\end{array}$ & $=4 \quad 10$ & \\
\hline \multirow{2}{*}{\multicolumn{8}{|c|}{ BARC type 2,3 or 5}} \\
\hline & & & $2.54(1.43-4.53)$ & 0.002 & & & \\
\hline$\geq 75$ years & $32(12.0)$ & $18(6.3)$ & $1.90(1.06-3.38)$ & 0.03 & & & 0.48 \\
\hline \multicolumn{8}{|c|}{ BARC type 3 or 5} \\
\hline$<75$ years & $16(2.3)$ & $8(1.2)$ & $1.96(0.84-4.58)$ & 0.12 & & - & 0.83 \\
\hline \multirow{2}{*}{\multicolumn{8}{|c|}{ BARC type 3}} \\
\hline & & & & & & & \\
\hline $\begin{array}{l}<75 \text { years } \\
>5 \text { years }\end{array}$ & $14(2.0)$ & $\begin{array}{l}5(0.7) \\
9(3.1)\end{array}$ & $\begin{array}{l}2.15(0.99-1.36) \\
1.29(0.53-3.11)\end{array}$ & 0.052 & & & 0.27 \\
\hline \multicolumn{8}{|c|}{ TIMI major or minor } \\
\hline$<75$ years & $13(1.9)$ & $6(0.9)$ & $2.12(0.81-5.57)$ & 0.13 & & & \\
\hline 275 years & $14(5.3)$ & $9(3.1)$ & $1.64(0.71-3.78)$ & 0.25 & & & 0.69 \\
\hline \multicolumn{8}{|c|}{ GUSTO moderate or severe } \\
\hline \multirow{3}{*}{$\begin{array}{l}<75 \text { years } \\
275 \text { years }\end{array}$} & $14(2.0)$ & $10(1.5)$ & $1.37(0.61-3.08)$ & 0.45 & & & \\
\hline & $18(6.8)$ & $9(3.1)$ & $2.11(0.95-4.70)$ & 0.07 & & & 0.45 \\
\hline & & & & & \multicolumn{3}{|c|}{$\begin{array}{l}\begin{array}{l}\text { 24-month DAPT } \\
\text { better }\end{array} \text {-month DAPT } \\
\text { better }\end{array}$} \\
\hline \multirow{2}{*}{ B } & 24-month & $\leq 6$-month & & & \multicolumn{2}{|c|}{$\mathrm{HR}(95 \% \mathrm{Cl})$} & \\
\hline & DAPT & DAPT & HR (95\% Cl) & $p$-value & $0.1 \quad 0.25 \quad 0.5$ & $2 \quad 4 \quad 10$ & $p$-interaction \\
\hline \multicolumn{8}{|c|}{ BARC type 2,3 or 5} \\
\hline$<75$ years & $30(4.5)$ & $11(1.7)$ & $2.73(1.37-5.44)$ & 0.004 & & & 0.99 \\
\hline \multirow{2}{*}{\multicolumn{8}{|c|}{$\begin{array}{l}275 \text { years } \\
\text { BARC type } 3 \text { or } 5\end{array}$}} \\
\hline & & & & & & & \\
\hline$<75$ years & $10(1.5)$ & $5(0.7)$ & $1.97(0.67-5.76)$ & 0.22 & & & \\
\hline \multirow{2}{*}{\multicolumn{8}{|c|}{$\begin{array}{l}275 \text { years } \\
\text { BARC type } 3\end{array}$}} \\
\hline & & & & & & & \\
\hline$<75$ years & $9(1.3)$ & $5(0.7)$ & $1.77(0.59-5.28)$ & 0.31 & & & 0.72 \\
\hline \multirow{2}{*}{\multicolumn{8}{|c|}{ TIMI major or minor }} \\
\hline & & & & & & & \\
\hline$<75$ years & $8(1.2)$ & $4(0.6)$ & $1.96(0.59-6.51)$ & 0.27 & ⺊ & $=$ & 0.65 \\
\hline \multirow{2}{*}{\multicolumn{8}{|c|}{ GUSTO moderat }} \\
\hline & & & & & & & \\
\hline & $8(1.2)$ & $5(0.7)$ & $1.57(0.51-4.79)$ & 0.43 & & $\longrightarrow$ & 0.18 \\
\hline \multirow[t]{2}{*}{$\geq 75$ years } & $14(5.4)$ & $3(1.1)$ & $4.91(1.41-17.10$ & 0.01 & & $=-$ & \\
\hline & & & & & $\begin{array}{l}\text { 24-month DAPT } \\
\text { better }\end{array}$ & $\begin{array}{l}\text { s6-month DAPT } \\
\text { better }\end{array}$ & \\
\hline
\end{tabular}

Figure 3. Analysis of safety outcomes stratified by age. A) Bleeding events at 24 months. B) Bleeding events from six to 24 months. BARC: Bleeding Academic Research Consortium; GUSTO: Global Utilization of Streptokinase and Tissue Plasminogen Activator for Occluded Arteries; TIMI: Thrombolysis In Myocardial Infarction

3) A strategy of 24-month DAPT compared with six-month DAPT was associated with a greater risk of the key safety endpoint of BARC type 2, 3 or 5 bleeding in both elderly and nonelderly patients. Although the relative magnitude of treatment effect on bleeding was similar, the absolute risk difference with prolonged DAPT was greater in elderly compared with younger participants.

DAPT is an evidence-based, guideline-recommended, standard of care treatment after PCI ${ }^{14}$. Recently, two large randomised trials, DAPT and PEGASUS-TIMI 54 (Prevention of cardiovascular

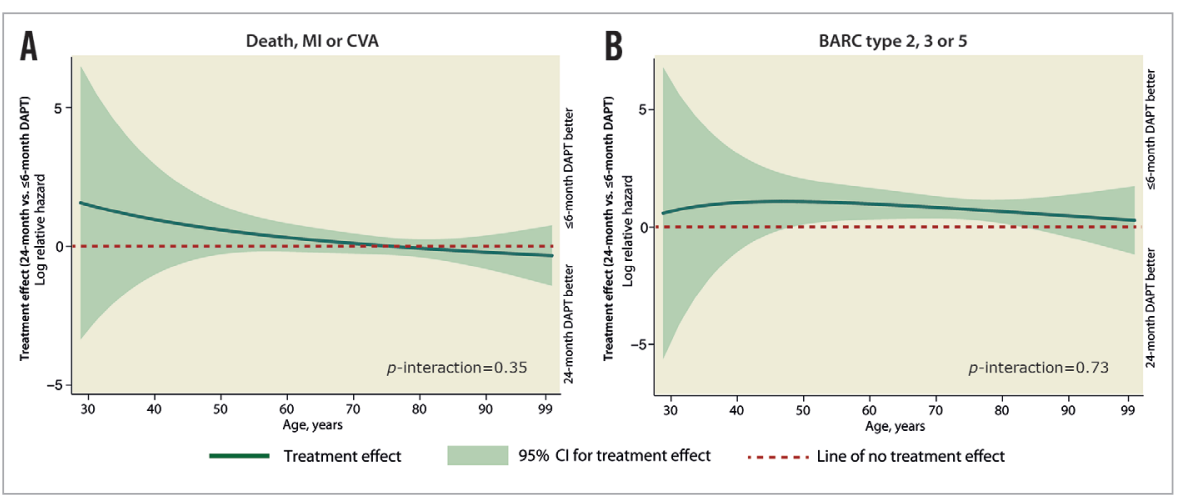

Figure 4. Fractional polynomial interaction for the primary efficacy and key safety endpoints. A) Death, MI or CVA. B) BARC type 2, 3 or 5 bleeding. The treatment-by-age interaction is analysed by considering age as a continuous variable. The green line represents the treatment effect of 24-month vs. six-month DAPT and the area represents the $95 \%$ CI of treatment effect. The dotted red line represents the no treatment effect. The comparison of 24-month vs. six-month DAPT is significant for the age values where the green area does not cross the line of no treatment effect. In this case, the effect of prolonged DAPT in increasing the risk of the key safety endpoint was significant for the range of 50 to 80 years. 
events in patients with prior heart attack using ticagrelor compared to placebo on a background of aspirin-thrombolysis in myocardial infarction 54), showed a significant reduction in ischaemic events with long-term DAPT among patients undergoing PCI as well as among high-risk patients with prior myocardial infarction ${ }^{7,9,15,16}$. Nevertheless, the optimal treatment duration of DAPT remains controversial as the protection afforded by extended DAPT in terms of ischaemic events is counterbalanced by an increase in bleeding complications $^{7,8}$. Although the PEGASUS-TIMI 54 trial reported consistent results in terms of the primary ischaemic endpoint according to age, elderly patients represented less than $15 \%$ of the overall population ${ }^{15}$. However, despite being formally not significant ( $\mathrm{p}$ for interaction $=0.09$ ), elderly versus non-elderly patients derived less ischaemic benefit from $90 \mathrm{mg}$ of ticagrelor vs. placebo. At variance, among participants allocated to ticagrelor $60 \mathrm{mg}$, elderly patients derived a similar magnitude of benefit to non-elderly patients with regard to the primary efficacy endpoint. A treatment-by-age heterogeneity for the primary endpoint according to age has been observed in the ISAR-SAFE ( $\mathrm{p}$ for interaction=0.03) and IVUS-XPL trials ( $p$ for interaction $=0.051$ ), favouring the use of short-term DAPT in elderly rather than younger patients ${ }^{17,18}$. However, the primary endpoint in both trials included a composite of ischaemic and bleeding events, which did not allow complete assessment of the benefit-risk ratio associated with DAPT in elderly patients.

We found that elderly patients experienced a greater risk of both ischaemic and bleeding events, with risk trajectories proceeding similarly with ageing. Such a pattern is similar to that described by Roe and colleagues in a cohort of patients with acute coronary syndrome managed without revascularisation ${ }^{19}$. Prolonged DAPT did not reduce the risk of ischaemic events among both elderly and non-elderly patients, which is in keeping with the results in the overall finding of the PRODIGY trial. However, interaction testing showed heterogeneity in treatment effect for the primary efficacy endpoint, with a possible harmful effect with 24-month DAPT in non-elderly subjects. In this regard, the higher risk of cardiac instead of non-cardiac death among younger patients randomised to 24-month DAPT, although not related to MI, remains biologically counterintuitive and difficult to explain. Such a finding could also be the result of variable categorisation rather than a direct effect, because the age-by-treatment interaction on a continuous basis was not significant at the fractional polynomial analysis.

Our study provides a nuanced interpretation for the alleged difference in the risk of bleeding associated with DAPT use among elderly patients. We found that prolonged DAPT had a similar effect on the key bleeding endpoint of BARC type 2, 3 or 5 among elderly and non-elderly patients at 24-month follow-up. However, owing to the higher rate of bleeding events, elderly patients had a greater increase in the absolute risk of BARC 2, 3 or 5 bleeding with 24-month DAPT, resulting in a lower NNTH (18 vs. 29). During the period between six and 24 months, the absolute risk difference in BARC 2, 3 or 5 bleeding tended to increase, as well as the difference in the NNTH (18 vs. 36). Taken together, these findings suggest that relative and absolute risks of bleeding should be disentangled in the decision process for DAPT duration in elderly people, by factoring the similar relative risk of bleeding associated with prolonged DAPT with the higher absolute risk difference due to the increased event rate.

\section{Limitations}

The results of this study have to be interpreted in the light of several limitations. First, our observations are based on subgroup populations within an overall trial, which failed to show the superiority of prolonged DAPT in the main population. Second, although there is general agreement that people $\geq 75$ years can be defined as "elderly", ageing is a continuous process and the cut-off of 75 years remains arbitrary. Nevertheless, we tried to accommodate this limitation by evaluating the age-by-treatment interaction also on a continuous basis. Furthermore, a cut-off of 65 years yielded similar results. Third, the group of elderly patients was relatively modest in size, and all the analyses should be considered as hypothesis-generating and exploratory in nature. However, it is noteworthy that the mean age in the PRODIGY trial was the highest across available trials with comparable design. This might explain the differential effect of elderly status on the risk of ischaemic events observed in this study compared with other trials enrolling relatively younger patients. Fourth, randomisation in the PRODIGY trial was not stratified by age.

\section{Conclusions}

In an all-comers population of PCI patients, elderly participants experienced a higher risk of ischaemic and bleeding events compared with their non-elderly counterparts with a comparable effect of ageing on the hazards of such events. Prolonging DAPT for 24 months was not associated with a significantly different risk of the primary efficacy endpoint among elderly and non-elderly patients. However, elderly patients seemed to derive a greater absolute risk of clinically relevant bleeding from prolonged DAPT than younger patients.

\section{Impact on daily practice}

Elderly status conveys a higher risk of both ischaemic and bleeding events. Although dual antiplatelet therapy increases the risk of bleeding in both elderly and non-elderly patients, the former group incurs a substantially higher event rate. The efficacy of prolonged dual antiplatelet therapy for the prevention of ischaemic events is not influenced by elderly status.

\section{Conflict of interest statement}

R. Piccolo has received a research grant from the Veronesi Foundation. G. Gargiulo has received a research grant from the European Association for Percutaneous Cardiovascular Interventions (EAPCI) and from the CardioPath $\mathrm{PhD}$ program. $\mathrm{S}$. Windecker has received research grants to the institution from Abbott, Biotronik, Boston Scientific, Biosensors, Medtronic, Edwards, and St. Jude. The other authors have no conflicts of interest to declare. 


\section{References}

1. Roth GA, Forouzanfar MH, Moran AE, Barber R, Nguyen G, Feigin VL, Naghavi M, Mensah GA, Murray CJ. Demographic and epidemiologic drivers of global cardiovascular mortality. $N$ Engl J Med. 2015;372:1333-41.

2. Andreotti F, Rocca B, Husted S, Ajjan RA, Ten Berg J, Cattaneo M, Collet JP, De Caterina R, Fox KA, Halvorsen S, Huber K, Hylek EM, Lip GY, Montalescot G, Morais J, Patrono C, Verheugt FW, Wallentin L, Weiss TW, Storey RF; ESC Thrombosis Working Group. Antithrombotic therapy in the elderly: expert position paper of the European Society of Cardiology Working Group on Thrombosis. Eur Heart J. 2015;36:3238-49.

3. Galasso G, De Servi S, Savonitto S, Strisciuglio T, Piccolo R, Morici N, Murena E, Cavallini C, Petronio AS, Piscione F. Effect of an invasive strategy on outcome in patients $\geq 75$ years of age with non-ST-elevation acute coronary syndrome. Am J Cardiol. 2015; 115:576-80.

4. Piccolo R, Giustino G, Mehran R, Windecker S. Stable coronary artery disease: revascularisation and invasive strategies. Lancet. 2015;386:702-13.

5. Montalescot G, Brieger D, Dalby AJ, Park SJ, Mehran R. Duration of Dual Antiplatelet Therapy After Coronary Stenting: A Review of the Evidence. J Am Coll Cardiol. 2015;66:832-47.

6. Piccolo R, Windecker S. Dual Antiplatelet Therapy in Percutaneous Coronary Intervention: A Tale of 2 Decades With New Perspectives in the Era of New-Generation Drug-Eluting Stents. Circ Cardiovasc Interv. 2016;9:e003587.

7. Navarese EP, Andreotti F, Schulze V, Kolodziejczak M, Buffon A, Brouwer M, Costa F, Kowalewski M, Parati G, Lip GY, Kelm M, Valgimigli M. Optimal duration of dual antiplatelet therapy after percutaneous coronary intervention with drug eluting stents: meta-analysis of randomised controlled trials. BMJ. 2015; 350:h1618.

8. Palmerini T, Benedetto U, Bacchi-Reggiani L, Della Riva D, Biondi-Zoccai G, Feres F, Abizaid A, Hong MK, Kim BK, Jang Y, Kim HS, Park KW, Genereux P, Bhatt DL, Orlandi C, De Servi S, Petrou M, Rapezzi C, Stone GW. Mortality in patients treated with extended duration dual antiplatelet therapy after drug-eluting stent implantation: a pairwise and Bayesian network meta-analysis of randomised trials. Lancet. 2015;385:2371-82.

9. Mauri L, Kereiakes DJ, Yeh RW, Driscoll-Shempp P, Cutlip DE, Steg PG, Normand SL, Braunwald E, Wiviott SD, Cohen DJ, Holmes DR Jr, Krucoff MW, Hermiller J, Dauerman HL, Simon DI, Kandzari DE, Garratt KN, Lee DP, Pow TK, Ver Lee P, Rinaldi MJ, Massaro JM; DAPT Study Investigators. Twelve or 30 months of dual antiplatelet therapy after drug-eluting stents. N Engl J Med. 2014;371:2155-66.

10. Valgimigli M, Campo G, Monti M, Vranckx P, Percoco G, Tumscitz C, Castriota F, Colombo F, Tebaldi M, Fuca G, Kubbajeh M, Cangiano E, Minarelli M, Scalone A, Cavazza C, Frangione A, Borghesi M, Marchesini J, Parrinello G, Ferrari R; Prolonging Dual Antiplatelet Treatment After Grading StentInduced Intimal Hyperplasia Study (PRODIGY) Investigators.
Short- versus long-term duration of dual-antiplatelet therapy after coronary stenting: a randomized multicenter trial. Circulation. 2012;125:2015-26.

11. Valgimigli M, Campo G, Percoco G, Monti M, Ferrari F, Tumscitz C, Zuffi A, Colombo F, Kubbajeh M, Cavazza C, Cangiano E, Tebaldi M, Minarelli M, Arcozzi C, Scalone A, Frangione A, Borghesi M, Marchesini J, Parrinello G, Ferrari R. Randomized comparison of 6- versus 24-month clopidogrel therapy after balancing anti-intimal hyperplasia stent potency in allcomer patients undergoing percutaneous coronary intervention Design and rationale for the PROlonging Dual-antiplatelet treatment after Grading stent-induced Intimal hyperplasia study (PRODIGY). Am Heart J. 2010;160:804-11.

12. Piccolo R, Pilgrim T, Heg D, Franzone A, Rat-Wirtzler J, Raber L, Silber S, Serruys PW, Jüni P, Windecker S. Comparative Effectiveness and Safety of New-Generation Versus EarlyGeneration Drug-Eluting Stents According to Complexity of Coronary Artery Disease: A Patient-Level Pooled Analysis of 6,081 Patients. JACC Cardiovasc Interv. 2015;8:1657-66.

13. Royston P, Sauerbrei W. Interaction of treatment with a continuous variable: simulation study of power for several methods of analysis. Stat Med. 2014;33:4695-708.

14. Authors/Task Force members, Windecker S, Kolh $P$, Alfonso F, Collet JP, Cremer J, Falk V, Filippatos G, Hamm C, Head SJ, Jüni P, Kappetein AP, Kastrati A, Knuuti J, Landmesser U, Laufer G, Neumann FJ, Richter DJ, Schauerte P, Sousa Uva M, Stefanini GG, Taggart DP, Torracca L, Valgimigli M, Wijns W, Witkowski A. 2014 ESC/EACTS Guidelines on myocardial revascularization: The Task Force on Myocardial Revascularization of the European Society of Cardiology (ESC) and the European Association for Cardio-Thoracic Surgery (EACTS)Developed with the special contribution of the European Association of Percutaneous Cardiovascular Interventions (EAPCI). Eur Heart J. 2014;35: 2541-619.

15. Bonaca MP, Bhatt DL, Cohen M, Steg PG, Storey RF, Jensen EC, Magnani G, Bansilal S, Fish MP, Im K, Bengtsson O, Oude Ophuis T, Budaj A, Theroux P, Ruda M, Hamm C, Goto S, Spinar J, Nicolau JC, Kiss RG, Murphy SA, Wiviott SD, Held P, Braunwald E, Sabatine MS; PEGASUS-TIMI 54 Steering Committee and Investigators. Long-term use of ticagrelor in patients with prior myocardial infarction. N Engl J Med. 2015;372: 1791-800.

16. Udell JA, Bonaca MP, Collet JP, Lincoff AM, Kereiakes DJ, Costa F, Lee CW, Mauri L, Valgimigli M, Park SJ, Montalescot G, Sabatine MS, Braunwald E, Bhatt DL. Long-term dual antiplatelet therapy for secondary prevention of cardiovascular events in the subgroup of patients with previous myocardial infarction: a collaborative meta-analysis of randomized trials. Eur Heart J. 2016;37: 390-9.

17. Schulz-Schupke S, Byrne RA, Ten Berg JM, Neumann FJ, Han Y, Adriaenssens T, Tölg R, Seyfarth M, Maeng M, Zrenner B, Jacobshagen C, Mudra H, von Hodenberg E, Wöhrle J, Angiolillo DJ, von Merzljak B, Rifatov N, Kufner S, Morath T, Feuchtenberger A, 
Ibrahim T, Janssen PW, Valina C, Li Y, Desmet W, Abdel-Wahab M, Tiroch K, Hengstenberg C, Bernlochner I, Fischer M, Schunkert H, Laugwitz KL, Schomig A, Mehilli J, Kastrati A; Intracoronary Stenting and Antithrombotic Regimen: Safety And EFficacy of 6 Months Dual Antiplatelet Therapy After Drug-Eluting Stenting (ISAR-SAFE) Trial Investigators. ISAR-SAFE: a randomized, double-blind, placebo-controlled trial of 6 vs. 12 months of clopidogrel therapy after drug-eluting stenting. Eur Heart J. 2015;36:1252-63.

18. Hong SJ, Shin DH, Kim JS, Kim BK, Ko YG, Choi D, Her AY, Kim YH, Jang Y, Hong MK; IVUS-XPL Investigators. 6-Month Versus 12-Month Dual-Antiplatelet Therapy Following
Long Everolimus-Eluting Stent Implantation: The IVUS-XPL Randomized Clinical Trial. JACC Cardiovasc Interv. 2016;9: 1438-46.

19. Roe MT, Goodman SG, Ohman EM, Stevens SR, Hochman JS, Gottlieb S, Martinez F, Dalby AJ, Boden WE, White HD, Prabhakaran D, Winters KJ, Aylward PE, Bassand JP, McGuire DK, Ardissino D, Fox KA, Armstrong PW. Elderly patients with acute coronary syndromes managed without revascularization: insights into the safety of long-term dual antiplatelet therapy with reduceddose prasugrel versus standard-dose clopidogrel. Circulation. 2013;128:823-33. 